\title{
GENETIC CONTROL OF STEROL ESTERIFICATION IN DEVELOPING WHEAT ENDOSPERM
}

\section{J,V. TORRES and F. GARCIA-OLMEDO}

Departamento de Bioquímica, E.T.S. Ingenieros Agrónomos, Universidad Politécnica, Madrid-3 (Spain)

\section{Summary}

1. The action of gene PIn, previously characterized by the sterol ester patterns of mature whole wheat kernels, has been found to be restricted to the endosperm and not to affect the embryo, the pericarp or the seed coat.

2. The dominant allele Pln, which determines a sterol ester pattern with palmitate as the main ester, is also responsible for a low level of free sterol at maturity. A high level of free sterol is associated with the recessive allele pln, which determines an ester pattern with linoleate as the main ester.

3 . Divergence between the two phenotypes starts at about 21 days after anthesis, when cell proliferation has been completed, the aleurone layer has differentiated, and only cell enlargement is taking place. A marked increase in esterification, mainly by palmitate, which is controlled by the dominant allele, is concomitant with a sharp decrease in free sterol.

4. The increased net esterification is non-specific with respect to 4-demethyl sterols, because it affects the four main ones, namely sitosterol, stigmasterol, campesterol and cholesterol.

Introduction

Sterols from higher plants are generally found in four different forms: free sterol, sterol ester, sterol glycoside and acylated sterol glycoside. The functions of these forms, which remain largely undefined, have been tentatively assigned mostly on the basis of indirect evidence.

Although there is considerable agreement about the roles of free sterols as

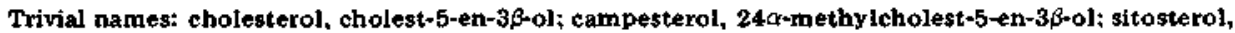

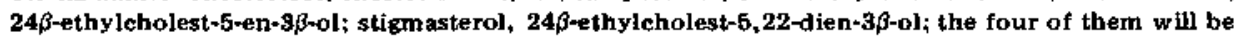
referred to as 4-demethyl sterols. 
biogenetic precursors [1] and as constituents of plant membranes [1-9], no such agreement exists concerning the conjugated forms, especially the sterol esters. Various hypotheses have been put forward in connection with the physiological functions of sterol esterification in plants. These are based on the observed composition changes during development and differentiation processes and on the subcellular distribution of sterol forms presented by different tissues. Thus, sterol esters have been implicated in sterol storage $[7,10]$, intracellular transport $[6,11]$, transference to other organs [7], and subtraction of free sterols from membranes in senescent tissues [7].

The characterization of genes affecting sterol esterification should contribute to clarify some of the above hypotheses. García-Olmedo and coworkers [12-15] have described a gene that controls the sterol ester pattern in the kernels of hexaploid wheat (Triticum aestivum L.). The PL phenotype pattern, which has palmitate as the main ester, is inherited as though determined by a dominant allele at a single locus $(P / n)$, while the linoleate pattern is inherited as a recessive allele $(p l n)$ [14]. Analysis of whole kernels of compensated nullitetrasomic and ditelosomic lines of Triticum aestivum cv. Chinese Spring showed that gene Pln is located in the short arm of chromosome 7D [15]. Palmitate was found to be the dominant ester in all lines, except those lacking chromosome 7D, which had linoleate as the main ester. The latter lines also showed a marked decrease in the esterified sterol of the whole kernel and an increase in free sterol. The presence of the short arm of chromosome 7D restored palmitate synthesis, increased the sterol ester level and decreased the free sterol [15].

We report here on the changes of free and conjugated sterols in the different structural parts of the wheat kernel during development and, especially, on the control by gene Pln of sterol esterification in the developing endosperm.

\section{Material and Methods}

\section{Biological material}

Two Triticum aestivum L. cultivars, Aragon 03 (PL phenotype) and Mara (L phenotype), were grown in an open field*. The approximate date of anthesis was tagged to each spike to be sampled. Kernel samples were taken at five developmental stages and at maturity. Stages 1 through 6 are defined in Fig. 1 by the percentages of final kernel dry weight and by the number of days after anthesis. Spikes were collected over dry ice, and the kernels were freeze-dried and stored under nitrogen at $-20^{\circ} \mathrm{C}$. For the last three stages, endosperm, coats (pericarp, seed coat and some aleurone) and embryo were dissected free-hand. Dry weight of mature kernels was $4.59 \mathrm{~g} / 100$ units for Aragon 03 and 3.97 $\mathrm{g} / 100$ units for Mara and their lipid content by Soxhlet extraction with ethyl ether was $2.23 \%$ and $2.35 \%$, respectively.

The $F_{1}$ seeds from a cross Aragon $03 \times$ Mara were selfed to obtain the $F_{2}$ generation. Endosperms from $F_{2}$ kernels were separated by hand-dissection.

* PL and L represent pajmitate-linoleate and linoleate, respectively. 


\section{Chemicals}

All chemicals used in this study were reagent grade and were used as obtained. Authentic samples used were cholestane, sitosterol, and campesterol (Serva); cholesterol palmitate (Fluka); cholesterol, stigmasterol, cholesterol oleate and linoleate (Merck). Gas liquid chromatography column packing was 3\% OV-101 over Varaport 80-100 mesh (Varian AG). Silica gel G for thin layer chromatography and all solvents were from Merck. The silylating reagent used was bis (trimethylsilyl) acetamide (Serva).

\section{Analytical procedures}

The main sterol esters, palmitate, oleate and linoleate, and the free sterol were extracted, separated by preparative thin-layer chromatography, eluted and quantitated by fluorimetry as previously described [15] .

Sterol glycosides and acylated sterol glycosides were extracted in duplicate from $300 \mathrm{mg}$ samples of finely ground material (Culatti mill) with acetone ( $5+5$ $w / v)$. Extractions were performed in teflon stoppered $5 \mathrm{ml}$ test tubes, first for $16 \mathrm{~h}$, with four $1 \mathrm{~min}$ periods of sonication in a cleaning bath (Varian AG), then for $30 \mathrm{~min}$, with $1 \mathrm{~min}$ of sonication. The solvent was evaporated in vacuo at $40^{\circ} \mathrm{C}$ and the extract was fractionated by thin-layer chromatography, using the solvent system chloroform/acetone/water $(30: 60: 2)$ described by Clayton et al. [16]. In order to locate the two glycoside fractions, extra samples were run in parallel in the same plate and sprayed with the $\mathrm{FeCl}_{3}$ specific reagent of Lowry [17]. The glycoside fractions were eluted with acetone and subjected to methanolysis according to Hølmer et al. [18]. The released sterol was separated and quantitated by fluorimetry as indicated above.

To quantitate individual 4-demethyl sterols, sterol forms were obtained from $3 \mathrm{~g}$ of finely ground material (Culatti mill) as described and methanolysis of all fractions was carried out. In the case of free sterol, this was done to facilitate removal of possible deglyceride contaminants. The 4-demethyl sterols were separated from the reaction mixture by thin-layer chromatography according to Kemp et al. [6]. The four main 4-demethyl sterols, sitosterol, stigmasterol, campesterol and cholesterol were analysed as free sterols and as trimethyl sylyl ethers as described by Grunwald [19].

\section{Results}

\section{Proportions of sterol forms in structural parts of the kernel}

The anatomical distribution of free and conjugated sterol in kernels of the two varieties, Aragon 03 (PL phenotype) and Mara (L phenotype), is recorded in Table I.

Sterol ester patterns of endosperms are qualitatively similar to those of the whole kernels; palmitate is the main ester in Aragon 03 and linoleate in Mara. Furthermore, the two varieties also differ in the proportions of free and esterified endosperm sterol ( $82 \%$ esterified in the PL phenotype, $67 \%$ free in the $\mathrm{L}$ phenotype) and in the levels of the glycosides (higher in the $\mathrm{L}$ phenotype).

Sterol forms distributions in the coats are essentially the same in the two 
TABLE I

ANATOMICAL DISTRUBITION OF STEROL FORMS IN KERNELS OF TWO TRITICUM AESTIVUM L. GENOTYPES

All results are expressed in mmol of sterol/100 $\mathrm{g}$ of dry matter. The coat fraction includes pericarp, seed coat and some aleurone.

\begin{tabular}{|c|c|c|c|c|c|c|}
\hline \multirow[t]{2}{*}{ Sterol form } & \multicolumn{2}{|c|}{ Endosperm } & \multicolumn{2}{|l|}{ Coat } & \multicolumn{2}{|l|}{ Embryo } \\
\hline & Aragon & Mara & Aragon & Mara & Aragon & Mara \\
\hline Free & 7.9 & 51.4 & 107.1 & 108.1 & 168.8 & 176.0 \\
\hline Palmitate & 28.4 & 4.1 & 11.6 & 12.5 & 57.9 & 53.1 \\
\hline Oleate & 9.4 & 6.3 & 9.9 & 10.6 & 520.9 & 506.4 \\
\hline Linoleate & 9.2 & 10.6 & 14.2 & 18.8 & 146.6 & 240.7 \\
\hline Glycoside & 1.0 & 2.2 & 0.5 & 0.5 & 1.4 & 2.6 \\
\hline Acyl-glycoside & 1.4 & 2.2 & 1.2 & 1.4 & 2.9 & 4.6 \\
\hline Total & 57.3 & 76.8 & 144.5 & 151.9 & 898.5 & 983.4 \\
\hline
\end{tabular}

varieties; $71-74 \%$ as free sterol, linoleate is the main ester, and total sterol level is $2-2.5$ times that of endosperm.

In the embryos of both varieties, $80-81 \%$ of the sterol is esterified and oleate is the main ester. Sterol glycosides are somewhat higher in the $L$ phenotype variety. The total sterol level is 12-16 times higher than in the endosperm.

Co-segregation of free sterol levels and steryl ester patterns.

Results in Table II show that the high level of endosperm free sterol present in the L phenotype parent (Mara) is inherited as though determined by a recessive allele at a single locus. All endosperms from the $F_{2}$ generation with high free sterol had the $\mathrm{L}$ sterol ester pattern and all those with low free sterol showed the PL phenotype pattern. Thus, no recombinant phenotypes were observed.

Evolution of sterol forms during kernel development

There are no significant differences between the two varieties in the accumulation of total kernel sterol during development (Fig. 1). The level of total

\section{TABLE II}

SEGREGATION OF ENDOSPERM FREE STEROL LEVEL AND STERYL ESTER PATTERN IN AN $F_{2}$ GENERATION FROM A CROSS ARAGON O3 (PL PHENOTYPE) $X$ MARA (L PHENOTYPE)

Endosperms were visually classified into PL (palmitate-linoleate) and L (linoleate) phenotypes after exposure of the thin-layer chromatograms to iodine vapor. The three main esters and the free sterol fraction of each endosperm were then quantitated by fluorimetry to determine limits of variation within each phenotype. The $58: 19$ segregation does not differ significantly from $3: 1, p<0.001$.

\begin{tabular}{|c|c|c|c|c|c|c|}
\hline \multirow[t]{2}{*}{ Phenotype } & \multirow{2}{*}{$\begin{array}{l}\text { Segration } \\
\text { no. of } \\
\text { endosperms }\end{array}$} & \multicolumn{4}{|c|}{ mol \% of sterol form $/ \mathrm{mol}$ of free + estexified } & \multirow{2}{*}{$\begin{array}{l}\text { Free + } \\
\text { esterified } \\
\text { mmol } / 100 \mathrm{~g}\end{array}$} \\
\hline & & Palmitate & Oleate & Linoleate & Free & \\
\hline PL & 58 & $39-51$ & $15-18$ & $17-25$ & $13-20$ & $29-36$ \\
\hline $\mathbf{L}$ & 19 & $4-8$ & $20-22$ & $22-25$ & $45-54$ & $22-26$ \\
\hline
\end{tabular}




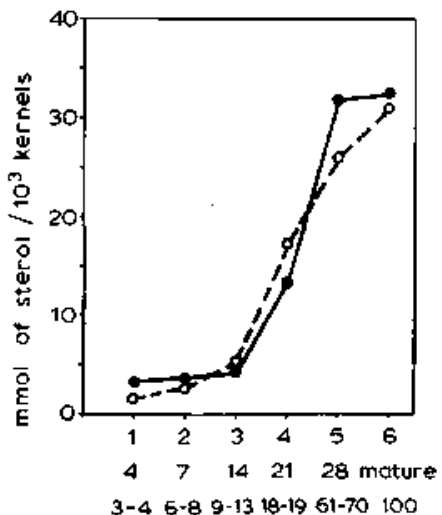

development stage

days after anthesis

\% of final dry weight

Fig. 1. Evolution of total kernel sterol during development. PL phenotype, Aragon 03 ( $\bullet$ ); L phenotype. Mara (o). Two 100 kemel samples were dried to constant weights at each stage to calculate the weight of $10^{3}$ kernels.

sterol (\% of dry matter) increases sharply during the initial stages of development and declines in the final ones.

The changes of endosperm sterol forms in the two genotypes during development are plotted on a per $10^{3}$ endosperms basis in Fig. 2. There is net synthesis of all forms in both varieties up to stage 5. From stage 5 to maturity, there is a considerable decrease in free sterol and an equally important increase
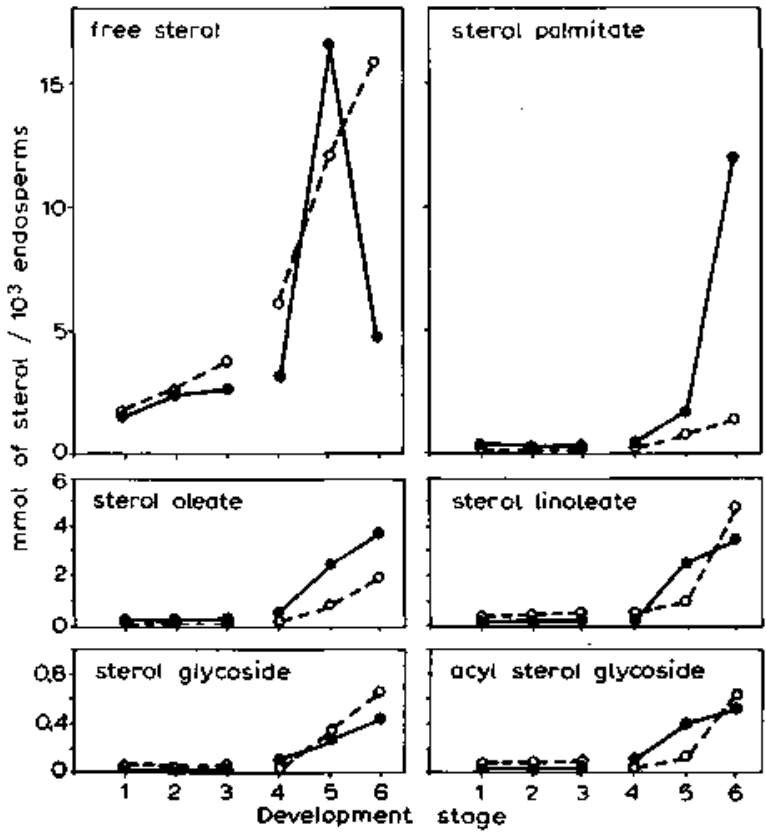

Fig. 2. Evolution of endosperm sterol forms during development. PL phenotype, Aragon 03 (૯): L phenotype, Mara (o). Development stages are defined as in Fig. 1. Two 25 kernel samples were dissected free-hand and the endosperms were dried to constant weight (stages 4-6). Data plotted at stages $1-3$ correspond to whole kernels. 
TABLE 1II

ANATOMICAL DISTRIBUTION OF 4-DESMETHYLSTEROLS IN KERNELS OF TWO TRITICUM AESTIVUM L, GENOTYPES

All results are expressed as mol $\% /$ mol of the four sterols in each tissue. The coats fractions includes pericarp, seed coat and some aleurone.

\begin{tabular}{|c|c|c|c|c|c|c|c|c|}
\hline \multirow[t]{2}{*}{ Tissue } & \multicolumn{2}{|c|}{ Cholesterol } & \multicolumn{2}{|c|}{ Campesterol } & \multicolumn{2}{|c|}{ Stigmasterol } & \multicolumn{2}{|c|}{ Sitosterol } \\
\hline & Mara & Aragon & Mara & Aragon & Mara & Aragon & Mara & Aragon \\
\hline Coats & 13.6 & 11.6 & 10.9 & 10.6 & 10.2 & 10.6 & 65.3 & 67.3 \\
\hline Embryo & 15.8 & 11.2 & 12.8 & 16.1 & 16.2 & 9.4 & 55.2 & 63.3 \\
\hline Endosperm & 7.6 & 13.3 & 3.8 & 4.6 & 13.6 & 14.6 & 75.0 & 67.0 \\
\hline
\end{tabular}

in sterol palmitate in Aragon 03 (PL phenotype), neither of which are observed in Mara ( $L$ phenotype). On a dry matter basis, the level of free sterol decreases in both phenotypes, but more sharply in the PL phenotype; the level of sterol palmitate increases and that of linoleate decreases in the PL phenotype, while the opposite occurs in the $\mathrm{L}$ phenotype; and the content of acylated and non-acylated glycosides decreases in Aragon 03 (PL phenotype) and increases in Mara (L phenotype).

No significant differences exist between the two varieties in the developmental changes in sterol forms of embryo and coats.

Total sterol level of embryo doubles from stage 5 to maturity, with an increase in the proportion of the esterified fraction from $67-71 \%$ to $80-81 \%$.

In the coats, practically no net sterol synthesis takes place from stage 4 to maturity, the only important change being an increase in the esterified fraction from $10-12 \%$ to $24-27 \%$.

\section{TABLE IV}

EVOLUTION OF 4-DEMETHYL STEROLS IN STEROL FORMS OF DEVELOPING ENDOSPERM FROM TWO TRITICUM AESTIVUM L. GENOTYPES

All results are expressed as mmol/1000 endosperms. Development stages are described in Fig. 1.

\begin{tabular}{|c|c|c|c|c|c|c|c|c|c|}
\hline \multirow[t]{2}{*}{ Sterol form } & \multirow{2}{*}{$\begin{array}{l}\text { Devel- } \\
\text { opment } \\
\text { stage }\end{array}$} & \multicolumn{2}{|c|}{ Sitosterol } & \multicolumn{2}{|c|}{ Stigmasterol } & \multicolumn{2}{|c|}{ Campesterol } & \multicolumn{2}{|c|}{ Cholesterol } \\
\hline & & Aragon & Mara & Aragon & Mara & Arason & Mara & Aragon & Mara \\
\hline Free & $\begin{array}{l}5 \\
6\end{array}$ & $\begin{array}{r}116.1 \\
33.1\end{array}$ & $\begin{array}{r}87.8 \\
137.7\end{array}$ & $\begin{array}{l}3.2 \\
5.0\end{array}$ & $\begin{array}{r}2.3 \\
11.9\end{array}$ & $\begin{array}{r}45.9 \\
1.2\end{array}$ & $\begin{array}{r}80.4 \\
5.5\end{array}$ & $\begin{array}{l}4.8 \\
0.9\end{array}$ & $\begin{array}{l}5.1 \\
0.9\end{array}$ \\
\hline Palmitate & $\begin{array}{l}5 \\
6\end{array}$ & $\begin{array}{l}24.4 \\
75.4\end{array}$ & $\begin{array}{r}5.8 \\
10.9\end{array}$ & $\begin{array}{r}0.5 \\
29.6\end{array}$ & $\begin{array}{l}0.2 \\
0.6\end{array}$ & $\begin{array}{l}8.3 \\
5.1\end{array}$ & $\begin{array}{l}2.4 \\
0.8\end{array}$ & $\begin{array}{r}0.5 \\
13.5\end{array}$ & $\begin{array}{l}1.7 \\
0.7\end{array}$ \\
\hline Oleate & $\begin{array}{l}5 \\
6\end{array}$ & $\begin{array}{l}16.2 \\
30.9\end{array}$ & $\begin{array}{r}3.8 \\
16.6\end{array}$ & $\begin{array}{l}0.1 \\
5.1\end{array}$ & $\begin{array}{l}0.1 \\
1.1\end{array}$ & $\begin{array}{l}6.6 \\
0.8\end{array}$ & $\begin{array}{l}2.1 \\
1.0\end{array}$ & $\begin{array}{l}2.1 \\
1.7\end{array}$ & $\begin{array}{l}0.6 \\
1.4\end{array}$ \\
\hline Linoleate & $\begin{array}{l}5 \\
6\end{array}$ & $\begin{array}{l}15.5 \\
30.5\end{array}$ & $\begin{array}{r}4.5 \\
86.0\end{array}$ & $\begin{array}{l}0.3 \\
4.8\end{array}$ & $\begin{array}{l}0.2 \\
7.2\end{array}$ & $\begin{array}{l}6.9 \\
1.6\end{array}$ & $\begin{array}{l}3.1 \\
1.7\end{array}$ & $\begin{array}{l}1.3 \\
1.7\end{array}$ & $\begin{array}{l}0.6 \\
2.2\end{array}$ \\
\hline Glycoside & $\begin{array}{l}5 \\
6\end{array}$ & $\begin{array}{l}1.5 \\
3.9\end{array}$ & $\begin{array}{l}1.8 \\
5.8\end{array}$ & $\begin{array}{l}0.1 \\
0.1\end{array}$ & $\begin{array}{l}0.1 \\
0.3\end{array}$ & $\begin{array}{l}0.6 \\
0.8\end{array}$ & $\begin{array}{l}0.7 \\
0.4\end{array}$ & $\begin{array}{l}0.3 \\
0.3\end{array}$ & $\begin{array}{l}0.2 \\
0.3\end{array}$ \\
\hline Acyl-glycoside & $\begin{array}{l}5 \\
6\end{array}$ & $\begin{array}{l}2.6 \\
4.7\end{array}$ & $\begin{array}{l}0.9 \\
0.7\end{array}$ & $\begin{array}{l}0.1 \\
0.2\end{array}$ & $\begin{array}{l}0.1 \\
0.1\end{array}$ & $\begin{array}{l}0.9 \\
0.3\end{array}$ & $\begin{array}{l}0.3 \\
0.5\end{array}$ & $\begin{array}{l}0.3 \\
0.3\end{array}$ & $\begin{array}{l}0.1 \\
0.4\end{array}$ \\
\hline Total & $\begin{array}{l}5 \\
6\end{array}$ & $\begin{array}{l}176.3 \\
178.5\end{array}$ & $\begin{array}{l}104.6 \\
212.7\end{array}$ & $\begin{array}{r}4.1 \\
44.8\end{array}$ & $\begin{array}{r}2.7 \\
21.2\end{array}$ & $\begin{array}{r}69.2 \\
9.5\end{array}$ & $\begin{array}{r}89.0 \\
9.9\end{array}$ & $\begin{array}{r}8.4 \\
18.4\end{array}$ & $\begin{array}{l}8.3 \\
5.9\end{array}$ \\
\hline
\end{tabular}




\section{Distribution of 4-demethyl sterols in sterol forms}

The relative proportions of the four main 4-demethyl sterols of wheat (sitosterol, stigmasterol, campesterol and cholesterol) in endosperms, coats, and embryos of the two varieties are presented in Table III. On a percentage basis, there are no important differences in 4-demethyl sterols between the two varieties or between tissues.

The 4-demethyl sterol distribution in endosperm of the two genotypes at development stages 5 and 6 are summarized in Table IV. At maturity, esterified/free sterol ratios are higher in the PL phenotype than in the $L$ phenotype; 9-10 times for sitosterol, stigmasterol and campesterol, and about 4 times higher for cholesterol. These ratios are lower and the differences between the two varieties much smaller at stage 5. Apart from this, each sterol shows a different trend. Free sitosterol decreases in Aragon 03 and increases in Mara; free stigmasterol increases in both varieties, but more markedly in Mara; free campesterol and cholesterol decrease in the two phenotypes. Esterified sitosterol, stigmasterol and cholesterol increase, while campesterol decreases, in the two varieties. Esterification is greater in Aragon 03 than in Mara mainly due to sterol palmitate synthesis.

\section{Discussion}

The present results show that the differences in sterol ester pattern controlled by gene Pln are confined to the endosperm and that the previously observed difference in kernel free sterol between euploid Chinese Spring wheat and lines lacking chromosome 7D [15], also exist between the PL and the L phenotype varieties and is equally restricted to the same tissue (Table I). The higher sterol level cosegregates with the L phenotype pattern (Table II), which means that both features are controlled by the same mendelian factor or by two closely linked factors. The first alternative is quite likely from a biochemical point of view, the accumulation of free sterol resulting from the less effective esterification of the $L$ phenotype. The significantly lower content of free plus esterified sterol in $\mathbf{F}_{2}$ kernels with $L$ phenotype versus PL phenotype kernels (Table II) can be interpreted as a feedback control by free sterol on its own synthesis. The possible association of the L phenotype pattern with greater content of sterol glycosides and acyl sterol glycosides (Table 1), could not be ascertained because we were not able to analyze simultaneously these fractions in single endosperms.

Two phases can be clearly distinguished in endosperm development [20]. The first phase ends 16-19 days after anthesis, when all cell division has stopped and a mature aleurone layer has been formed [20,21]. The second phase, which continues to maturity, is characterized by an active starch and protein synthesis, and by cell enlargement. The increase in the level of total and free sterol in the kernel (dry matter basis) coincides with the cell proliferation phase. The decrease in total sterol level of the whole kernel and of the endosperm, as well as the increase in the proportion of esterified sterol, take place in the cell enlargement phase. The decrease in total sterol level can be explained as a dilution effect brought about by a greater relative rate of non-sterol dry matter synthesis, especially starch and protein. 
Divergence of the two sterol phenotypes occurs in the cell enlargement phase, starting shortly after stage 4 . A decrease in free sterol, which coincides with an increase in sterol palmitate can be observed in Aragon 03 (Fig. 2). At stage 5, the distribution of 4-demethyl sterols in the free sterol fraction is still quite similar in both varieties but that of the palmitate fraction, which is undergoing a sharp increase in the PL phenotype, shows already substantial differences between both phenotypes (Table IV).

Data in Table IV also show that the greater esterification by palmitate controlled by allele Pln affects the four main 4-demethyl sterols and is therefore non-specific in this respect.

Our results are compatible in general, but difficult to compare in detail, with the semiquantitative data of Skarsaune et al. [22] on the free and esterified sterol of wheat flour and bran, obtained at different maturation stages, because the two kernel fractions were obtained by milling and therefore are not equivalent to those obtained by us.

In view of the drastic differences in sterol forms distribution between the different parts of the kernel (Table I), it should be stressed that data on evolution on steroi forms in developing or germinating whole seeds is very difficult to interpret in physiological terms. This seems to be the case in the work on the development of the soybean seed [23] and of the Calendula officinalis seed [10]. However, some similarities with the present case can be discerned: an increase of the level of esterified sterol and a decrease in that of all other sterol forms in the final stages of development.

It has been speculated that the observed accumulation of sterol esters during certain physiological processes could be related to membrane disorganization and/or sterol storage $[7,10,24,25]$. Indeed, the increased esterification in the final stages of endosperm development could play the role of destabilizing membranes in connection with cell enlargement, dehydration or even the final cell disorganization, although its timing would be more consistent with the first two alternatives. We have previously reported that most $T$. aestivum varieties have the PL phenotype and that only $L$ phenotype is found in $T$. durum [13]. This could be related to the fact that the latter species is best adapted and practically restricted to semiarid climates, while the first one grows well in colder and more humid regions. Less destabilization would be needed in the semiarid climate. Admitedly, this hypothesis in highly speculative, but would be consistent with our observations concerning the sensitivity of developing endosperms with the different sterol genotypes to $n$-butanol and the polyene antibiotic filipin [26] .

With respect to the possible storage role of the esterified fractions, we are investigating at present the effect of gene Pln on germination.

\section{References}

1 Heftman, E. (1971) Lipids 6, $128-133$

2 Grunwald, C. (1968) Plant Physiol. 43, 484-488

3 Grunwald, C. (1971) Plant Phystol. 48, 653-655

4 Mudd, J.B. and Kleinschmidt, M.G. (1970) Plant Physiol, 45, 517-518

5 Hendrix, D.L. and Higinbothan, N. (1973) Plant Physiol. 52, 93-97

6 Kemp, R.J., Goad, L.J, and Mercer, E.J. (1967) Phytochemistry, 6, 1609-1615 
7 Duperon, P. (1971) Physiol. Veg. 9, 373-399

8 Bush, P.B. and Grunwald, C. (1972) Plant Physiol. 50, 69-72

9 Hartman, M.-A., Ferne, M., Gigot, C., Brand, R. and Benveniste, P. (1973) Physiol, Veg. $11,209-230$

10 Kazpryk, Z., Pyrek, J. and Turowska, G. (1968) Acta Biochim. Polon, 15, $149-158$

11 Goodwin. T.W. (1967) in Biochemistry of Chloroplast (Goodwin, T.W., ed.), Vol, II, pp. 721-733, Acad. Press, New York

12 García-Olmedo, F. (1965) Bol. Inst. Nac. Invest. Agron, 25, 409-416

13 Garefa-Faure, R., García-Olmedo, F. and Vallejo, J.M. (1968) J. Sci. Fed. Agric. 19, $322-324$

14 Garcfa-Olmedo, F, (1968) Nature 220, 1144-1:45

15 Torres, J.V, and Garcia-Olmedo, F, (1974) Plant Sci. Lett. 3, 213-217

16 Clayton, T.A., MacMurray, T.A. and Morrison, W.R. (1970) J. Chromatogr. 47, 277-281

17 Lowry, R.R. (1968) J. Lipid Res. 9, 397

18 Hфlmer, G., Ory, R.L. and Hoy, C.-E. (1973) Lipids, 8, 277-283

19 Grunwald. C. (1970) Anal. Biochem. 34, 16-23

20 Evers, A.D. (1970) Ann. Bot. 34, 546-555

21 Jennings, A.C. and Morton, R.K. (1963) Aust. J. Biol. Sel. 16, 332-341

22 Skarsaune, S.K., Youngs, V.L. and Gilles, G.A. (1970) Cereal Chem. 47, 533-544

23 Katayama, M. and Katoh. M. (1973) Plant Cell Physiol. 14, 681-688

24 Duperon, P. and Duperon, R. (1969) C.R. Acad. Sci. 269, 157-160

25 Duperon, R., Duperon, P, and Thiersault, M. (1971) C.R. Acad. Sci. 273, 580-583

26 Carbonero, P., Torres, J.V. and Gareja-Olmedo, F. (1975) FEBS Lett. 56, $198-201$ 